\title{
An Interactive Web-Gis Development for Risk Tsunami Hazard Potential Information In Pangandaran Village West Java
}

\author{
Juan Andrian, Arif Ismail, Iwan Setiawan, Shafira Himayah \\ Universitas Pendidikan Indonesia \\ arifismail@upi.edu
}

\section{Article History}

accepted 31/08/2020

\begin{abstract}
In 2006, a tsunami disaster occurred on the coast of Pangandaran Regency which claimed up to 664 fatalities. A large number of people died due to lack of information in knowing areas that are prone to tsunami disasters. Therefore, a geographic information system for the tsunami disaster is needed to facilitate the Pangandaran community to find out areas that are prone to tsunami disasters. In making a geographic information system web tsunami disaster using GeoServer, PostgreSQL and LeafletJS. Making a geographic information system web is done in several ways, namely, entering shapefile data into a database and then displaying it on a map server. The results of creating a web of the tsunami geographic information system contain information on land use, public facilities, hamlet boundaries, road networks, river networks and tsunami disaster mitigation.
\end{abstract}

Keywords: pangandaran, tsunami, leaflet, geoserver, postgresql.

\section{Abstrak}

Pada tahun 2006, terjadi bencana tsunami di pesisir Kabupaten Pagandaran yang memakan korban hingga 664 korban jiwa yang meninggal. Banyaknya jumlah jiwa yang meninggal diakibatkan kurangnya informasi dalam mengetahui daerah yang rawan terhadap bencana tsunami. maka dari itu, dibutuhkan sebuah web sistem informasi geografis bencana tsunami untuk memudahkan masyarakat pangandaran untuk mengetahui daerah yang rawan terhadap bencana tsunami. Dalam pembuatan web sistem informasi geografis bencana tsunami menggunakan GeoServer, PostgreSQL dan LeafletJS. Pembuatan web sistem informasi geografis ini dilakukan dengan beberapa cara yaitu, memasukan data shapefile ke dalam database lalu menampilkannya ke dalam server peta. Hasil dari pembuatan web sistem informasi geografis bencana tsunami ini berisikan informasi penggunaan lahan, fasilitas umum, batas dusun, jaringan jalan, jaringan sungai dan mitigasi bencana tsunami.

Kata kunci: pangandaran, tsunami, leafletjs, geoserver, postgresql

Social, Humanities, and Education Studies (SHEs): Conference Series https://jurnal.uns.ac.id/shes 


\section{PENDAHULUAN}

Pada tanggal 17 Juli 2006 pukul 08.19 pagi, terjadi bencana tsunami di pesisir Kabupaten Pangandaran. Berdasarkan data yang terdapat di Badan Meteorologi Klimatologi dan Geofisika (BMKG). Diawali dengan gempa sebesar 7.7 SR dirasakan oleh sebagaian besar penduduk pantai selatan Jawa Barat. Tsunami melanda kawasan pantai selatan Pulau Jawa sepanjang 500 km. Bencana Tsunami merusak desa-desa di pantai selatan Jawa Barat, yaitu : Cipatujah (Tasikmalaya), Pangandaran (Ciamis), dan lokasi wisata pantai Pangandaran. Terdapat 664 jiwa korban meninggal dari tsunami yang terjadi di Pangandaran (BMKG, 2018).

Dari informasi dan besarnya korban jiwa dari bencana-bencana tsunami yang telah terjadi sebelumnya. Maka diperlukan pengetahuan tentang kebencanaan dan cara mengantisipasi apabila bencana datang. Dalam suatu analisis spasial, Sistem Informasi Geografis dapat dimanfaatkan untuk mengetahui daerah dan wilayah yang rawan terhadap bencana serta dapat membantu dalam menentukan wilayah yang aman untuk melakukan evakuasi. Dengan memanfaatkan Sistem Informasi Geografis dapat mengurangi dampak kerugian terhadap ancaman bencana yang dialami suatu wilayah (BPBD, 2016).

Banyaknya jumlah penduduk di Desa Pangandaran dan ditambah dengan wisatawan yang berlibur di Desa Pangandaran, maka dibutuhkan sebuah informasi yang bisa di akses secara cepat dan tepat untuk mengetahui lokasi yang aman, apabila kedepannya terdapat suatu potensi bencana tsunami. Selain itu, Desa Pangandaran belum memiliki sebuah website resmi yang dikelola oleh pemerintah desa tersebut dan website suatu desa sangat diperlukan sebagai penunjang fasilitas informasi yang ada di Desa Pangandaran.

Dalam pembuatan web sistem informasi geografis menggunakan software seperti PostgreSQL, Geoserver dan LeafletJS. Software yang digunakan merupakan software yang bersifat open source. Penggunaan dari PostgreSQL untuk menyimpan database dari data-data yang digunakan dalam pembuatan web, kemudian kegunaan dari Geoserver yaitu server yang digunakan untuk keperluan Sistem Informasi Geografis seperti berbagi, memproses serta mengedit data berformat geospasial, dikembangkan dengan menggunakan bahasa Jawa, dan terakhir kegunaan dari Leaflet JS untuk pembuatan peta interaktif dalam web menggunakan bahasa pemrograman Jawa. (Dj and Cahyono, 2016).

Pada penelitian sebelumnya tentang WebGIS kebencanaan, para peneliti menggunakan software PostgreSQL, Geoserver dan Leaflet JS dalam pembuatan WebGIS, contoh adanya penelitian yang menggunakan software tersebut adalah pada penelitian Sistem Informasi Multi Ancaman Bencana Alam di Aceh (Nasaruddin dkk, 2011). Dimana hasil dari penelitian ini adalah web yang dibuat oleh peneliti mampu menampilkan sebagian besar peta-peta multi ancaman yang ada di Aceh. Kemudian contoh penelitian lainnya adalah penelitian Aplikasi Web Sistem Informasi Geografis Untuk Multi Risiko Bencana Aceh (Islamadina, 2012), hasil dari penelitian tersebut adalah dapat menampilkan tingkatan risiko bencana alam yang terdiri dari peta-peta rawan bencana, peta-peta kerentanan, peta-peta kapasitas dan peta-peta risiko bencana serta menginformasikan jenis bencana yang berupa bencana abrasi, banjir, gunung api, gempa bumi, tanah longsor, epidemi, kekeringan, kebakaran, angin topan dan tsunami,

Untuk itu dibutuhkan sebuah sistem informasi yang dibuat untuk memberikan informasi tentang potensi dan resiko bencana tsunami suatu daerah. Tujuan dari penelitian ini adalah untuk penyusunan basis data menggunakan PostgreSQL, Untuk pengolahan data spasial ke dalam server menggunakan geoserver dan untuk penyusunan tampilan WebGIS menggunakan LeafletJS. Informasi ini sangat 
diperlukan agar masyarakat bisa melakukan evaluasi secara mandiri apabila terjadi suatu kebencanaan. Informasi ini diharapkan dapat mempermudah masyarakat Desa Pangandaran dalam mengetahui daerah yang sangat rawan, dan dengan mudah diakses oleh masyarakat Desa Pangandaran. Kemudian dengan adanya sistem informasi spasial dapat memberikan masukan dalam pengambilan kebijakan mitigasi bencana tsunami. Maka dari itu dengan kebutuhan yang diperlukan oleh masyarakat pangandaran, maka dibuatlah penelitian dengan judul "Pembuatan Web Sistem Informasi Geografis Potensi Bencana Tsunami di Desa Pangandaran". Penelitian ini bertujuan untuk penyusunan basis data menggunakan postgresql, untuk pengolahan data ke server menggunakan geoserver, dan untuk penyusunan webgis menggunakan leafletjs.

\section{Persiapan Penelitian}

\section{METODE}

Dalam tahap persiapan Penelitian mengenai Pembuatan Web Sistem Informasi Geografis Potensi Bencana Tsunami di Desa Pangandaran terdapat 3 kegiatan yang dilakukan peneliti yaitu, mengidentifikasi masalah, kemudian menentuan lokasi penelitian dan mencari literatur berupa jurnal nasional, jurnal internasional, buku dan skripsi yang berkaitan dengan pembuatan tugas akhir ini dan juga digunakan peneliti untuk mendukung penulisan penelitian ini.

\section{Input Data Penelitian}

Didalam tahapan input data penelitian, di bahas berupa metode penelitian yang dibagi ke dalam beberapa tahap yaitu sebagai berikut:

a. Teknik Perolehan data

Dalam kajian Pembuatan Web Sistem Informasi Geografis Potensi Bencana Tsunami di Desa Pangandaran peneliti harus mempersiapkan beberapa data, baik data primer maupun data sekunder. Data Primer yang digunakan merupakan data hasil penelitian kemah kerja mahasiswa prodi survei pemetaan dan informasi geografis 2017 sedangkan data sekunder diperoleh dari instansi yang mendukung dalam penulisan penelitian ini, seperti BIG.

b. Teknik Pengolahan Data.

Terdapat beberapa tahapan pengolahan data sebagai berikut :

1) Tahap Pengolahan Data di QGIS

2) Tahap Penyusunan Basis Data/Atribut di PostgreSQL

3) Tahap Pengolahan Data di Geoserver

4) Tahap pembuatan WebGIS dan Coding Web

5) Uji web dan Hasil akhir WebGIS

6) Tahap Mengubah WebGIS localhost menjadi WebGIS online

7) Uji web

\section{HASIL DAN PEMBAHASAN}

\section{Penyusunan Basis Data Menggunakan PostgreSQL}

Grand Design ini adalah rancangan basis data yang akan digunakan dalam pembuatan WebGIS. Dalam merancang suatu basis data harus memperhatikan beberapa hal yaitu, tabel dalam basis data tidak boleh terdapat data yang sama atau data ganda, setiap tabel dalam basis data harus mempunyai kolom yang unik yang akan dijadikan sebagai primary key, dan rancangan basis data harus disesuaikan dengan data yang diperlukan. Terdapat 9 data vektor yang digunakan dan disimpan datanya di dalam PostgreSQL, data-data tersebut yaitu, penggunaan lahan, ancaman tsunami, 
kapasitas tsunami, kerentanan tsunami dan risiko tsunami yang berbetuk polygon. Batas administrasi, jaringan jalan, jaringan sungai yang berbetuk polyline dan fasilitas umum yang berbentuk point.

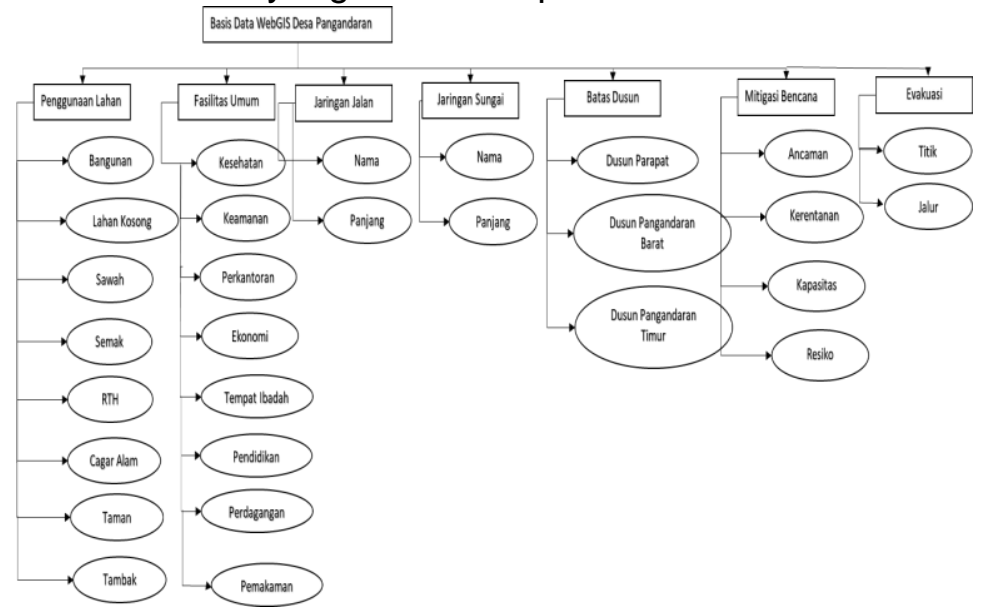

Gambar 1. Rancangan Basis Data

\section{Pengolahan Data Spasial ke Server Menggunakan Geoserver}

Dalam pengolahan data spasial ke server menggunakan geoserver. Geoserver harus terkoneksikan terlebih dahulu dengan PostgreSQL yang digunakan sebagai penyimpanan basis data. Setelah Geoserver dan PostgreSQL terkoneksikan kemudian mengimport data yang terdapat di dalam PostgreSQL ke dalam geoserver untuk dirubah data spasial menjadi data server yang berbentuk .json dalam melakukan koneksi antara PostgreSQL dengan Geoserver menggunakan PostGIS sebagai plugin yang digunakan untuk menyambungkan dua aplikasi tersebut.

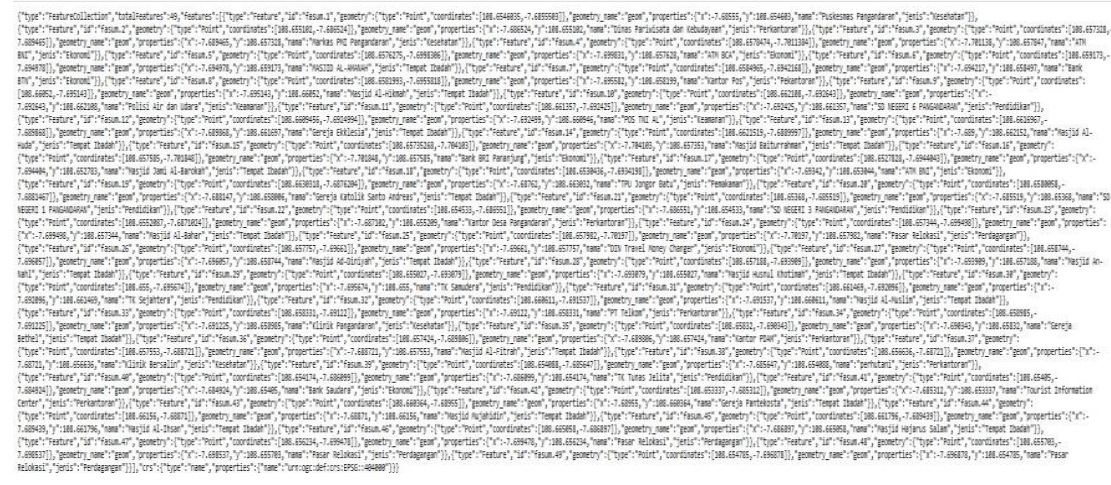

Gambar 2. Script Pengolahan Data

\section{Penyusunan Tampilan Web Menggunakan Leaflet JS}

Gambar 3. merupakan tampilan utama dari WebGIS Desa Pangandaran disusun menggunakan LeafletJS pada halaman utama tersebut menampilkan basemap dari Open Street Map, kemudian menampilkan juga data vektor dari penggunaan lahan, jaringan jalan, jaringan sungai, fasilitas umum, batas dusun serta toponimi dari dusun Desa Pangandaran. Pada WebGIS Desa Pangandaran pengguna dapat mengoprasikan peta interaktif dengan mudah dan leluasa, pada Gambar 3. adalah peta interaktif dari pembuatan web sistem informasi geografis potensi bencana tsunami di Desa Pangandaran yang berisi data informasi berdasarkan kebutuhan pengunjung web (user) 
yang terkait dengan informasi yang terdapat di dalam peta interaktif. Dan alamat website dari Desa Pangandaran adalah https://desapangandaran.000webhostapp.com/index.php

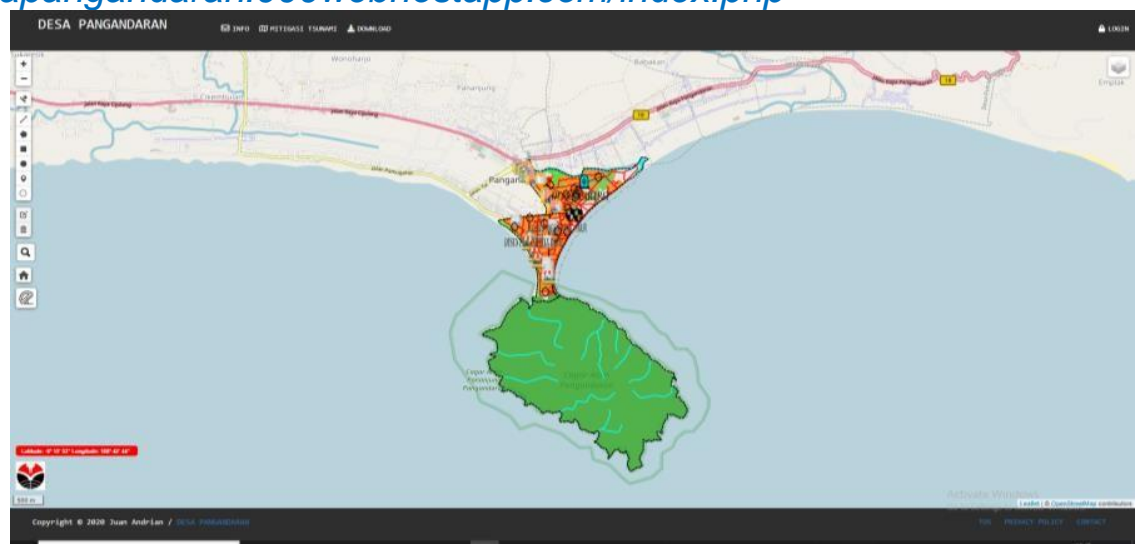

\section{Fitur Dalam WebGIS}

Gambar 3. Tampilan WebGIS Desa Pangandaran

\section{a. Potensi Ancaman Tsunami Desa Pangandaran}

Untuk Potensi ancaman tsunami di Desa Pangandran semua kawasannya merupakan daerah yang memiliki ancaman yang tinggi, aspek yang dilihat dari ancaman ini adalah ketinggian, kemiringan lereng, jarak dari sungai dan jarak dari pantai. Tingginya ancaman tsunami di Desa Pangandaran dikarenakan dekatnya Desa Pangandaran dengan Samudra Hindia atau Pantai Pangandaran. Ketinggian tempat yang relatif datar di Desa Pangandaran membuat daerah ini tidak ada tempat yang aman apabila terjadi bencana tsunami. Dengan banyaknya bangunan di Desa Pangandaran dipastikan juga banyak masyarakat yang tinggal maupun bekerja di Desa Pangandaran, maka diperlukan suatu jaringan jalan yang baik agar lebih mudah dan cepat dalam melakukan evakuasi ke tempat yang aman, sehingga jumlah korban yang terdampak ancaman tsunami dapat diminimalisir. Pembuatan peta ancaman ini berdasarkan historis dari bencana tsunami di aceh yang memiliki tinggi gelombang hingga 30 meter.

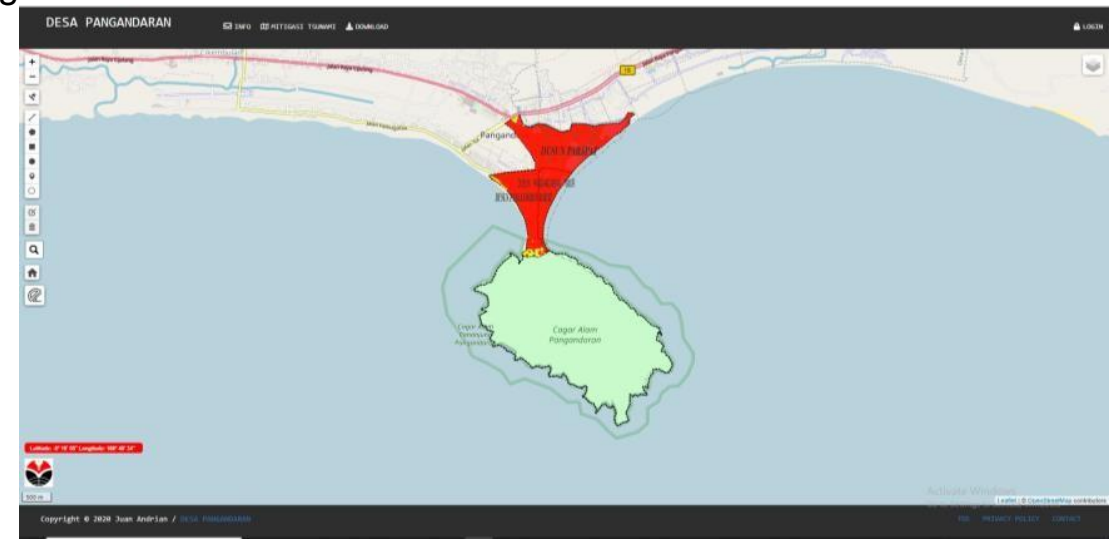

Gambar 4. Tampilan Ancaman Desa Pangandaran

\section{b. Kapasitas Desa Pangandaran}

Kapasitas bencana tsunami di Desa Pangandaran diperoleh dari hasil wawancara dengan pemerintah, masyarakat dan sekolah, dari hasil yang diperoleh terdapat dua dusun, yaitu Dusun Parapat dan Dusun Pangandaran Timur yang memiliki kategori hampir siap dan terdapat satu dusun yaitu Dusun Pangandaran Barat yang memiliki kategori kurang siap 
dalam menghadapi bencana tsunami.

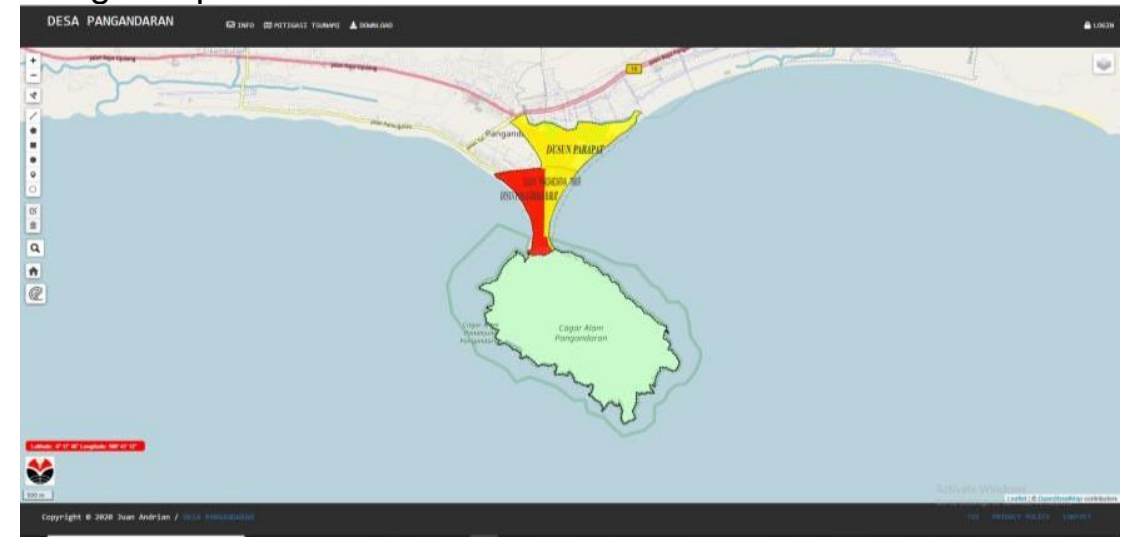

Gambar 5. Tampilan Kapasitas Desa Pangandaran

\section{c. Kerentanan Desa Pangandaran}

Kerentanan bencana tsunami di Desa Pangandaran terdapat perbedaan kerentanan di setiap dusunnya dimana Dusun Parapat memiliki kategori kerentanan yang rendah, Dusun Pangandaran Barat memiliki kategori sedang dan untuk Dusun Pangandaran Timur memilki kategori kerentanan tinggi.

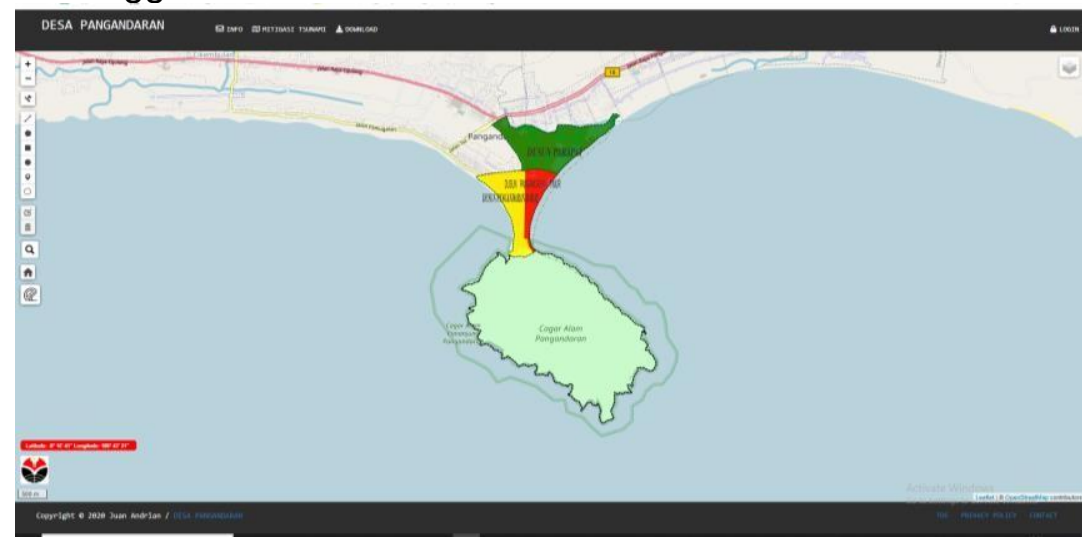

\section{d. Risiko Desa Pangandaran}

\section{Gambar 6. Tampilan Kerentanan Desa Pangandaran}

Risiko bencana tsunami diperoleh dari overlay data ancaman, kapasitas dan kerentanan mengikuti rumus dalam pembuatan peta risiko dan hasil yang didapatkan di dua dusun, yaitu Dusun Pangandaran Timur dan Dusun Pangandaran Barat di Desa Pangandaran memiliki risiko yang tinggi dan satu dusun, yaitu Dusun Parapat yang memiliki risiko yang sedang dan dapat disimpulkan juga bahwa di desa pangandaran ini memiliki risiko yang tinggi apabila bencana tsunami datang. Untuk melakukan pengurangan risiko bencana maka yang harus dilakukan adalah dengan cara memperkecil ancaman kawasan, mengurangi kerentanan kawasan yang terancam dan meningkatkan kapasitas kawasan yang terancam. 


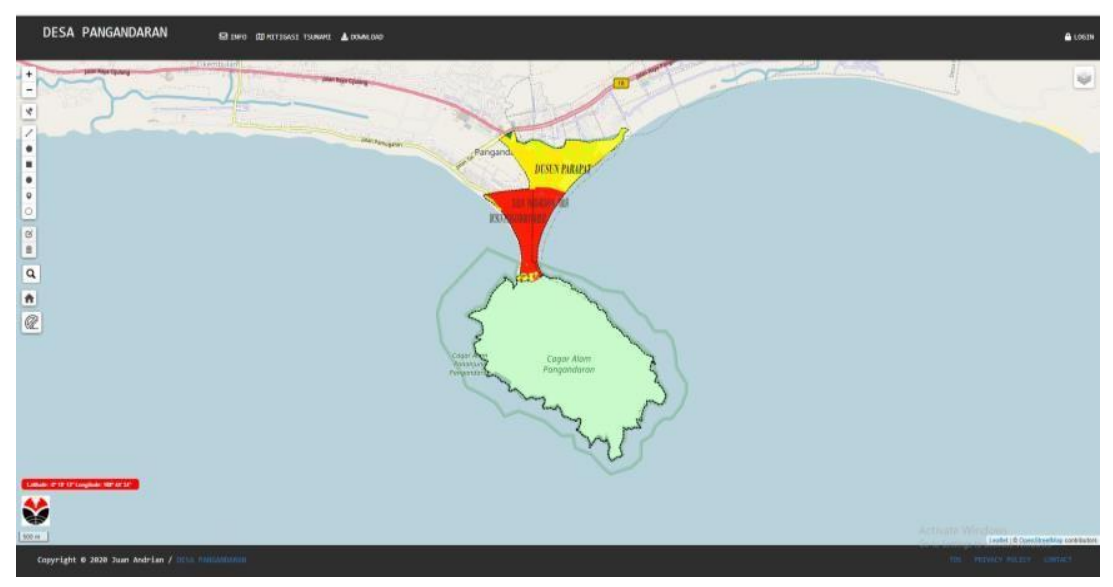

Gambar 7. Tampilan Risiko Desa Pangandaran

\section{e. Fasilitas Umum Desa Pangandaran}

Fasilitas Umum yang terdapat di Desa Pangandaran diantaranya terdapat tempat ibadah baik masjid maupun gereja, kantor-kantor seperti kantor desa pangandaran, kantor dinas pariwisata, dan kantor perhutani, kemudian terdapat juga sarana pendidikan, sarana kesehatan, sarana keamanan dan saranan ekonomi.

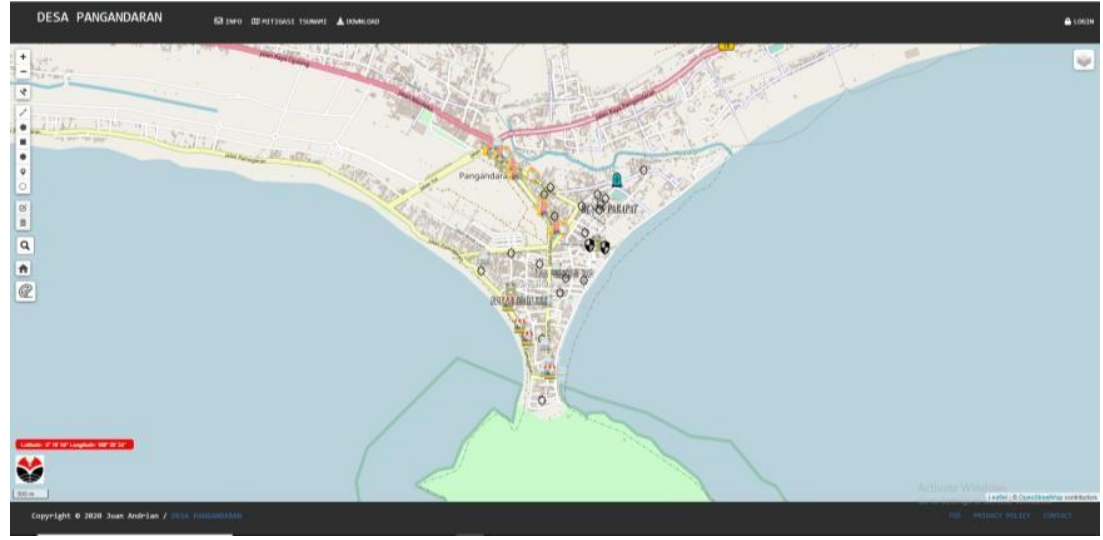

Gambar 8. Tampilan Fasilitas Umum Desa

\section{Pangandaran}

f. Batas Administrasi, Jaringan Jalan dan Jaringan Sungai

Terdapat 3 dusun yang terdapat di Desa Pangandaran, yaitu Dusun Parapat, Dusun Pangandaran Timur dan Dusun Pangandaran Barat. Untuk Jaringan jalan sudah terpetakan sesuai dengan jalan yang terdapat di Desa Pangandaran dan terdapat satu sungai utama yaitu Sungai Cikidang. 


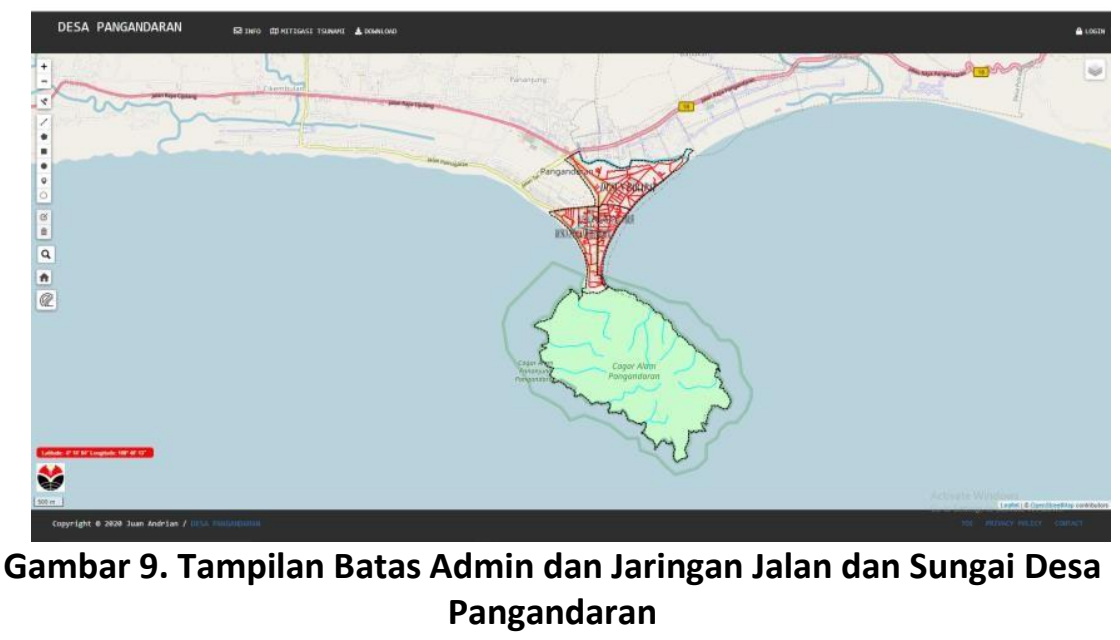

\section{g. Penggunaan Lahan}

Terdapat beberapa jenis penggunaan lahan di Desa Pangandaran yaitu: bangunan, cagar alam, lahan kosong, ruang terbuka hijau, sawah, semak belukar, taman, dan tambak. Untuk penggunaan lahan yang paling luas adalah cagar alam yaitu sebesar 522.8 ha dengan fungsi penggunaan lahan sebagai tempat konservasi, dan juga sebagai daya tarik wisata. Selanjutnya untuk penggunaan lahan bangunan memiliki luas 125.9 ha, fungsi dari penggunaan lahan bangunan yaitu, pemukimam, perkantoran, perdagangan dan jasa, tempat kesehatan, tempat ibadah, tempat keamanan, dan tempat pendidikan.

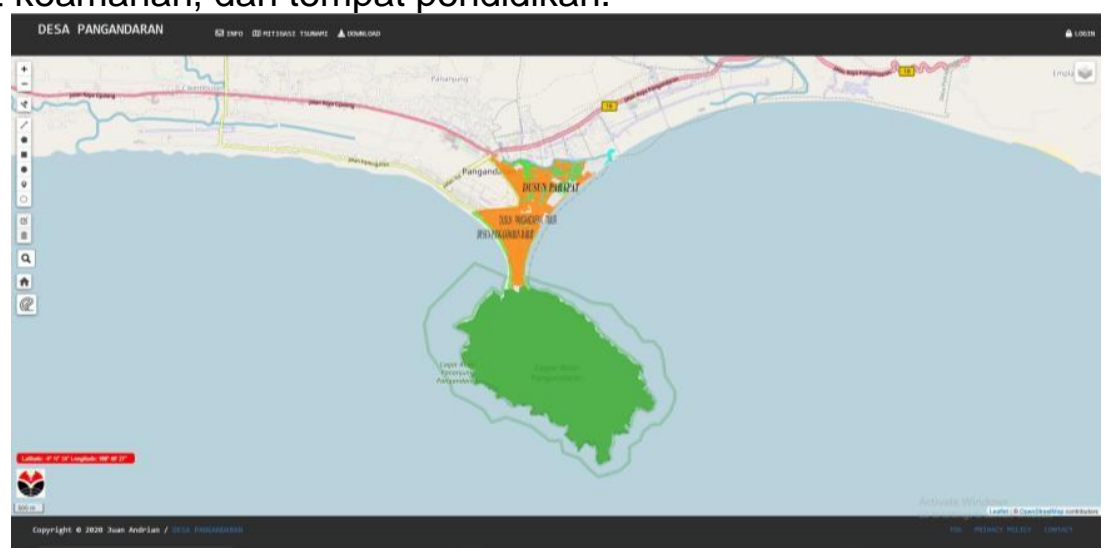

Gambar 10. Tampilan Penggunaan Lahan Desa Pangandaran

\section{Uji Web}

First Contentful Paint adalah waktu di mana gambar atau teks pertama muncul, disini untuk kecepatannya adalah 1,6 detik. Speed Index menunjukkan seberapa cepat isi halaman terlihat jelas. Semakin rendah nilainya semakin bagus. Untuk disini kecepatannya 3,4 detik. Time to Interactive adalah waktu pertama yang menunjukkan sebuah halaman dianggap interaktif secara penuh, kecepatannya disini sebesar 3,2 detik. Largest Contenful Paint mengukur kapan konten utama dari sebuah halaman muncul. Disini untuk kecepatannya adalah 3,9 detik. Total Waktu Pemblokiran menandakan waktu suatu halaman yang diblokir untuk merespons input pengguna seperti klik mouse, tap layar, atau penekanan keyboard, disini kecepatannya adalah 130 milidetik. Pergeseran tata letak kumulatif menunjukan pergeseran sebuah tampilan web disuatu perangkat, untuk pergeserannya sebesar $0 \mathrm{~mm}$. 
Jika dipersentasekan maka kecepatan webgis yang digunakan dalam desktop adalah 54 persen.

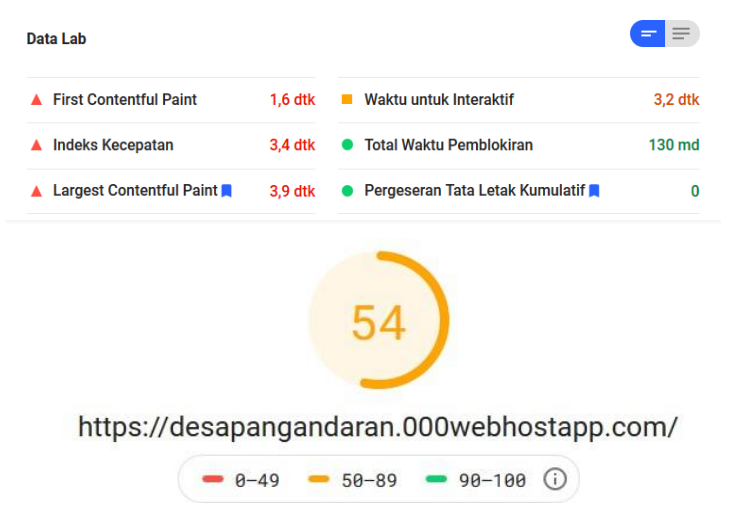

\section{Gambar 11. Kecepatan Web SIMPULAN}

Berdasarkan hasil penelitian ini maka dapat disimpulkan beberapa hal yaitu:

1. Dari hasil pembuatan WebGIS potensi bencana tsunami di Desa Pangandaran dapat menampilkan hasil informasi geografis seperti batas administrasi, penggunaan lahan, jaringan jalan, jaringan sungai, fasilitas umum dan mitigasi bencana tsunami Desa Pangandaran.

2. Pembuatan WebGIS potensi bencana di Desa Pangandaran ini dirancang berbasis web sehinggga ketersediaan informasi lebih mudah untuk diperoleh

3. Sistem Web yang dirancang sudah bisa diakses secara online meskipun masih dalam hostingan domain gratis

4. Pembuatan WebGIS potensi bencana tsunami di Desa Pangandaran ini datanya masih dapat diperbarui sesuai dengan perkembangan zaman dan bisa selalu (up to date).

\section{DAFTAR PUSTAKA}

Adil, A. 2017. Sistem Informasi Geografis. Yogyakarta: Penerbit Andi

Alvien, Rahmenda. 2017. "Pembuatan Aplikasi Sebaran Lokasi Kos Berbasis Webgis Menggunakan Google Map Api (Studi Kasus: Area Kampus Universitas Diponegoro)." UNDIP 6: 9.

Aminullah, Ridwan, Andri Suprayogi, and Abdi Sukmono. 2018. "Jurnal Geodesi Undip" 7: 11

Badan Penanggulangan Bencana Daerah (2016, 8 Agustus)."Pemanfaatan SIG (System Information Geografis) Untuk Mitigasi Bencana".Kab.Probolinggo.

Badan Meteorologi Klimatologi dan Geofisika.2019."Katalog Tsunami Indonesia Tahun 416-2018".Jakarta

Budiawan, and Muchammad Irawan. 2010. "Aplikasi Gis Berbasis Web Menggunakan Geoserver Pada Sistem Informasi Trafo Gardu Induk Di PIn Surabaya," January.

Dj, Webie Ni Maja, and Agung Budi Cahyono. 2016. "Perancangan Sistem Informasi Geografis Zona Nilai Tanah Berbasis Web Menggunakan Leaflet Javascript Library (Studi Kasus: Kecamatan Kenjeran, Kecamatan Gubeng, Kecamatan Tambak Sari dan Kecamatan Bulak, Kota Surabaya, Jawa Timur)." Jurnal Teknik ITS 5 (2): A809-16. 
Islamadina,Raihan., Nasaruddin.2012." Aplikasi Web Sistem Informasi Geografis Untuk Multi Risiko Bencana Aceh". Jurnal Rekayasa Elektrika Vol. 10, No. 1, April.

Maanari,J.I., R. Sengkey., F.Wowor., Y.D.Y Rindengan.2013."Perancangan Basis Data Perusahaan Distribusi dengan Menggunakan Oracle".Jurnal Teknik Elektro dan Komputer,UNSRAT,Manado-95115.

Marjuki, Bramantiyo. 2014. Sistem Informasi Geografi Menggunakan QGIS 2.0.1. Vol.

2.

Nasaruddin, Khairul Munadi, Dedi Yuliansyah.2011."Sistem Informasi Multi Ancaman

Bencana Alam di Aceh". UPN "Veteran" Yogyakarta. ISSN: 1979-2328

Nugroho, Adi.2004."Perancangan dan Implementasi Basis Data". Bandung : Informatika,

Peraturan Kepala Badan Nasional Penanggulangan Bencana Nomor 02 Tahun 2012 Tentang Pedoman Umum Pengkajian Risiko Bencana

Peraturan Pemerintah Nomor 21 Tahun 2008 Tentang Penyelenggaraan Penanggulangan Bencana Daerah.

Rusli, Irjan dan Ariska Rudyanto.2010."Pemodelan Tsunami Sebagai Bahan Mitigasi Bencana Studi Kasus Sumenep dan Kepulauannya".Jurnal Neutrino Vol.2:No.2.

Sulistyo, Bambang.2016."Peranan Sistem Informasi Geografis Dalam Mitigasi Bencana Tanah Longsor". Bengkulu

Tanjaya, Evan J, Silvia Rostianingsih, and Andreas Handojo. 2015. "Pemetaan Surabaya Heritage Dengan Geographic Information System," 4.

Wiwik Levitasari. 2017. "KAJIAN PENDAHULUAN Penggunaan Basis Data Spasial Objek Pajak Bumi Dan Bangunan Berbasis Open Source (Studi Kasus: Kelurahan Tembalang)" 6: 10.

Yuliani, Sylvia Tri, Bambang Sudarsono, and Arwan Putra Wijaya. 2016. "Aplikasi Sistem Informasi Geografis (Sig) Untuk Pemetaan Pasar Tradisional Di Kota Semarang Berbasis Web." UNDIP 5: 9. 